\title{
Sequestration of Nonylphenol in Sediment from Bohai Bay, North China
}

\author{
FEN JIN $,{ }^{\dagger}, \ddagger$ JIANYING HU $,{ }^{*},{ }^{\dagger}$ \\ JINLIN LIU, ${ }^{\dagger}$ MIN YANG, ${ }^{*,}$ ‡ \\ FU WANG, ${ }^{\S}$ AND HONG WANG ${ }^{\S}$ \\ College of Urban and Environmental Sciences, Peking \\ University, Beijing 100871, China, State Key Lab of \\ Environmental Aquatic Chemistry, Research Center for \\ Eco-Environmental Sciences, Chinese Academy of Sciences, \\ Beijing 100085, China, Tianjin Institute of Geology and \\ Mineral Resources, Tianjin 300170, China
}

Received June 22, 2007. Revised manuscript received November 12, 2007. Accepted November 16, 2007.

The ubiquity of nonylphenol (NP) in aquatic environments has been well documented, and the long-term fate of NP in sediments is a concern from the viewpoint of risk assessment due to its endocrine-disrupting effects. This paper reports on the assessment of long-term fate of NP in marine sediments by determining extractable and nonextractable fractions of NP in surface sediments and a sediment core from Bohai Bay, North China. The extractable fraction was operationally defined as the fraction of NP that was extracted with a solvent mixture of methanol/methylene chloride, and the nonextractable fraction was the portion of NP that can be released from the sediments by alkaline hydrolyzing after the initial solvent extraction. The total concentrations (extractable and nonextractable) of NP were $3.4-34.3 \mathrm{ng} / \mathrm{g} \mathrm{dw}$ in the surface sediments and 2.2-17.7 ng/g dw in the sediment core. Depending on the sedimentation time, the percentage of nonextractable NP relative to the total NP in the core ranged from 38 to $99 \%$. Based on the relationship between the percentage of nonextractable NP in sediments and sedimentation time, the sequestration rate of NP in the sediment core from Bohai Bay was estimated to be $0.94 \% \cdot \mathrm{a}^{-1}$. These results have important implications in understanding the geochemical fate of NP in sediments.

\section{Introduction}

Sequestration is the process which includes intraorganic matter and intraparticle diffusion in sediment/soil, which are believed to render contaminants less available for interactions with biological systems (1), as exemplified by laboratory studies of several insecticides (1), 4-nitrophenol (2), and polycyclic aromatic hydrocarbons (PAHs) such as phenanthrene and pyrene $(3,4)$. The extent of sequestration for chemicals was expressed as the extractability by mild extraction (3), which was affected by time, i.e., aging. Under laboratory conditions, the time-dependent decline in the extractable quantity of ${ }^{14} \mathrm{C}$-labeled organic chemicals from soil by a mild extraction has been demonstrated to be a useful

* Address correspondence to either author: Phone: (J.H.); 86-1062923475(M.Y.). Fax: 86-10-62765520 (J.H.); 86-10-62923475 (M.Y.). E-mail: hujy@urban.pku.edu.cn (J.H.); yangmin@rcees.ac.cn (M.Y.). ${ }^{\dagger}$ Peking University.

₹ Chinese Academy of Sciences.

$\$$ Tianjin Institute of Geology and Mineral Resources. approach to provide evidence for sequestration of chemicals in soil (2-5). In field investigations, however, the chemical degradation procedures such as alkaline hydrolysis and boron tribromide $\left(\mathrm{BBr}_{3}\right)$ treatment were generally applied to extract the nonextractable proportion of chemicals which could not be extracted by a mild extraction as exemplified by hexachlorophene $(6,7), 2,2$-bis(chlorophenyl) -1,1,1-trichlorethane (DDT) (8), and benzotriazoles (9).

Nonylphenol (NP) is the anaerobic biodegradation product of nonylphenol polyethoxylates (NPEOs) surfactants in aquatic environments, and it is of particular concern because of its endocrine-disrupting effects in aquatic organisms, mammals, and birds. Over the past few decades, thousands of marine and freshwater sediments have been analyzed, which demonstrated that the sediment was a major sink for NP (10). Therefore, it is important to elucidate the sequestration processes of NP in sediments because the long-term fate of NP is a vital criterion for assessing its ecological risks (11-17). Many studies have focused on the fate of NP in the environment such as the spatial and temporal distributions, and clarified both concentration levels at a regional scale and the temporal variation by historic record in field assessments $(15,18,19)$. The studies on the characterized temporal distribution of NP have especially emphasized the recent increased $(19,20)$ or decreased input $(15)$ due to the changes in usage and legal regulation in different countries. However, these results are all induced based on the extractable fraction of NP in sediments, i.e., the amounts that can be extracted with mild organic solvents. In fact, part of NP in sediments could be nonextractable by covalently binding to organic matter as exemplified by several other phenolic compounds such as 4-nitrophenol (2) and hexachlorophene $(6,7)$.

In this paper, nonextractable $\mathrm{NP}$ ( $\left.\mathrm{NP}_{\text {nonextractable }}\right)$ and extractable $\mathrm{NP}\left(\mathrm{NP}_{\text {extractable }}\right)$ were first differentiated by a mild extraction using a mixture of organic solvents (methanol and methylene chloride) followed by alkaline hydrolysis of surface sedimentary samples and a well-dated sedimentary core from Bohai Bay, North China. The sequestration rate, which was expressed as the variation of $\mathrm{NP}_{\text {nonextractable }}$ percentage in total NP with sedimentation time, was estimated, and the contents of total organic carbon (TOC) and black carbon (BC) in the sediments were also determined to better understand potential sequestration mechanisms. The results obtained in this study have important implications in understanding the long-term fates of NP in sediments.

\section{Materials and Methods}

Materials. NP (technical grade), a mixture of compounds with branched side chains, was purchased from Kanto Chemicals (Tokyo, Japan). And 4- $n$-nonylphenol (4- $n$-NP), used as the internal standard for analyzing NP, was obtained from Kanto Chemicals (Tokyo, Japan). Standard stocking solutions were prepared in acetonitrile. N,O-bis-(trimetylsilyl) trifluoroacetamide (BSTFA) reagent was obtained from Supelco (Bellefonte, PA).

Methylene chloride, acetonitrile, acetone, hexane, 2-propanol, and methanol were all HPLC grade obtained from Fisher Chemical Co. (Shanghai, China). Ultra pure water was made by the Easypure UV compact ultrapure system at a resistivity of $18.2 \mathrm{M} \Omega / \mathrm{cm}$. All the glassware was rinsed with $n$-hexane and acetone of pesticide residue grade and then baked in a muffle furnace at $400{ }^{\circ} \mathrm{C}$ for $4 \mathrm{~h}$ before use to avoid contamination.

Sediment Sampling. Figure S1 in the Supporting Information (SI) shows the sampling map for sedimentary samples. 
TABLE 1. Concentrations $(\mathrm{ng} / \mathrm{g} \mathrm{dw})$ of Extractable and Nonextractable NP in Surface Sediments from Bohai Bay, North China

\begin{tabular}{ccc} 
& \multicolumn{2}{c}{ concentration $(\mathbf{n g} / \mathbf{g} \mathbf{d w})$} \\
\cline { 2 - 3 } sites & $\mathbf{N P}_{\text {extractable }}$ & $\mathbf{N P}_{\text {nonextractable }}$ \\
I & 7.0 & 27.3 \\
J & 2.2 & 9.7 \\
K & 1.4 & 8.6 \\
L & 0.7 & 5.0 \\
M & 1.1 & 10.3 \\
N & 1.8 & 7.6 \\
O & 1.6 & 7.5 \\
P & 2.0 & 9.0 \\
Q & 1.3 & 6.5 \\
R & 1.6 & 13.0 \\
S & 2.3 & 18.8 \\
T & 1.3 & 17.9 \\
U & 2.2 & 26.8 \\
V & 1.5 & 5.0 \\
W & 0.4 & 3.0
\end{tabular}

Fifteen surface sediments ( $0-30 \mathrm{~cm}$ beneath the surface) were collected from the Bohai Bay in September of 2002. The sedimentary core was collected from Bohai Bay (Station A: $\mathrm{N} 38^{\circ} 17902^{\prime}$, E $117^{\circ} 48005^{\prime}$ ) using a 6 -cm diameter box corer in the summer of 2000. A stainless steel static gravity corer was employed to minimize the disturbance of the surface sediment layer. The core was sectioned at $2.5 \mathrm{~cm}$ intervals to the depth of $55 \mathrm{~cm}$ and at $5 \mathrm{~cm}$ intervals thereafter, and all samples were stored at $-20^{\circ} \mathrm{C}$ until extraction was carried out.

Extractable Fraction. Prior to chemical degradation, all sedimentary samples of 10-20 g air-dried and homogenized sediments were mixed with $20 \mathrm{~g} \mathrm{Na}_{2} \mathrm{SO}_{4}$ and spiked with recovery surrogate $(4-n-\mathrm{NP})$. Then the spiked samples were Soxhlet extracted first with a solvent mixture of methanol/ methylene chloride $(3: 7)$ for $24 \mathrm{~h}$. The extracts were rotoevaporated and reconstituted with $3 \mathrm{~mL}$ hexane. The $3 \mathrm{~mL}$ extract was passed through aminopropyl silica cartridges (500 $\mathrm{mg}, 6 \mathrm{~mL}$, Supelco) conditioned with $9 \mathrm{~mL}$ acetone, $3 \mathrm{~mL}$ methylene chloride, and $9 \mathrm{~mL}$ hexane. After the extract of the sedimentary sample was passed through the cartridge, a $1 \mathrm{~mL}$ rinse of hexane was added. The cartridge was eluted with $8 \mathrm{~mL}$ hexane/2-propanol $(90: 10 \mathrm{v} / \mathrm{v})$. The eluent was nitrogen-evaporated to dryness and reconstituted by $0.4 \mathrm{~mL}$ hexane, and was derivatized by adding $100 \mu \mathrm{LBSTFA}$ reagent to analyze NP. This fraction was operationally defined as the extractable fraction in this paper.

The procedure described above was validated by recovery ( $90 \%$ for NP), and the surrogate recovery of $4-n$-NP in the sedimentary samples was $95 \%$. The concentrations reported here have not been corrected for recovery. Precision was estimated at better than $20 \%$ based on analysis of three replicate samples.

Nonextractable Fraction. The chemical degradation procedures were sequentially carried out basically according to the alkaline hydrolysis and $\mathrm{BBr}_{3}$ treatment described in previous papers $(8,9)$. Briefly, the pre-extracted sediment samples $(5.0 \mathrm{~g}$ ) were placed in $22 \mathrm{~mL}$ vials, and $180 \mathrm{mg} \mathrm{KOH}$ dissolved in a mixture of $0.3 \mathrm{~mL}$ water and $12 \mathrm{~mL}$ methanol was added. Then the closed vials were heated at $105^{\circ} \mathrm{C}$ for $24 \mathrm{~h}$. After cooling, the supernatant liquid was decanted, and the solid residue was washed twice with $3 \mathrm{~mL}$ methanol. And then, $8 \mathrm{~mL}$ water was added, and the mixed solution was acidified to $\mathrm{pH} 3-5$ by addition of $300 \mu \mathrm{L}$ hydrochloric acid. Subsequently the solution was extracted with $5 \mathrm{~mL}$ hexane five times. The combined hexane layers were rotoevaporated to dryness, and reconstituted by $0.5 \mathrm{~mL}$ hexane. The final extract was derivatized by adding $100 \mu \mathrm{L}$ BSTFA

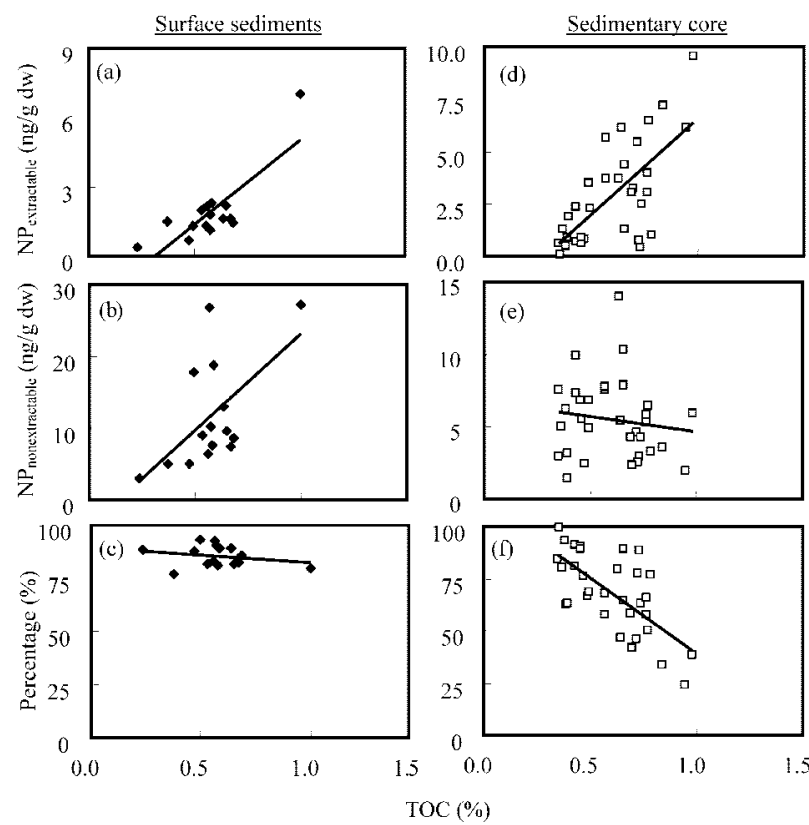

FIGURE 1. Relationships between concentrations of $\mathrm{NP}_{\text {extractable, }}$ $\mathbf{N P}_{\text {nonextractable, }}$ and percentage of $\mathbf{N P}_{\text {nonextractable }}$ and total organic carbon (TOC) content in sediments. The lines represent linear regression in surface sediments $(\bullet)$ and sedimentary core $(\square)$. (a) $\mathrm{NP}_{\text {extractable, }} p<0.0001, r^{2}=0.662$; (b) $\mathrm{NP}_{\text {nonextractable, }} p=$ $0.018, r^{2}=0.347$; (c) the percentage of $\mathrm{NP}_{\text {nonextractable }}$ relative to total NP, $p=0.432, r^{2}=0.058$; (d) $\mathrm{NP}_{\text {extractable, }} p<0.0001, r^{2}=$ 0.466; (e) $\mathrm{NP}_{\text {nonextractable, }} p=0.403, r^{2}=0.020$; (f) the percentage of $\mathrm{NP}_{\text {nonextractable }}$ relative to total NP, $p<0.0001, r^{2}=0.461$.

reagent (21) to analyze NP by GC-MS analysis. For $\mathrm{BBr}_{3}$ treatment, sediment samples $(2.0 \mathrm{~g})$ were extracted for $2 \mathrm{~h}$ using $8 \mathrm{~mL} 1.0 \mathrm{~mol} / \mathrm{L} \mathrm{BBr}_{3}$ solution in a water bath. The process of cleanup and concentrating was same as mentioned-above.

To validate whether chemical degradation procedures degraded NP itself, we applied the two processes to the reference material of NP. It was found that no alteration of NP was observed in the extracts after alkaline hydrolysis as illustrated in SI Figure S2(b), whereas $\mathrm{BBr}_{3}$ treatment degraded NP as shown in SI Figure S2(c). Thus, only alkaline hydrolysis procedure was applied to all sedimentary samples in this study, and the nonextractable NP was designated to the fraction of NP that was released by alkaline hydrolysis from sediments. This part of NP reflects the covalently bound NP (via ester bonds), and NP noncovalently incorporated into organic matter.

Analysis. The instrumental conditions for analyzing NP and $4-n-\mathrm{NP}$, and the quantitation and quality assurance/ quality control (QA/QC) are all provided in the Supporting Information.

Dating of the Core Sediment. Data of dating in this study were quoted from Wang et al. (23) and Li et al. (24). Briefly, the specific activities of the isotope ${ }^{137} \mathrm{Cs}$ and ${ }^{210} \mathrm{~Pb}$ in different slices of the core were measured in the different slices by direct gamma assay. And the sediment chronologies for the core were inferred based on a correlation of $\mathrm{Pb}$ isotopes profiles, depending on the apparent sedimentation rate in the core. The depth of the surface mixed layer $(7 \mathrm{~cm})$ was chosen by direct observation, and the constant initial concentration (CIC) model was fitted between ${ }^{210} \mathrm{~Pb}$ flux and depth excluding the surface mixed layer. The average sedimentation rate in the core (A) was $3 \mathrm{~cm} \cdot \mathrm{a}^{-1}$ according to the profile of $\mathrm{Pb}$ isotope.

TOC. TOC was measured by the high temperature combustion method. Dry sediments (about $5 \mathrm{mg}$ ) were put 

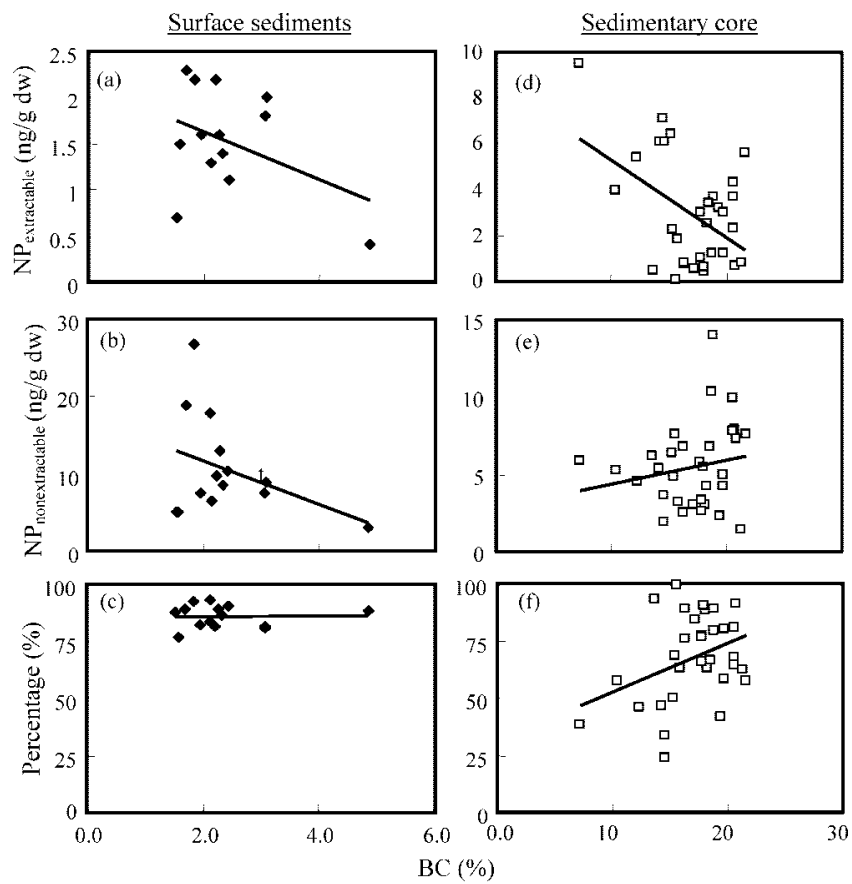

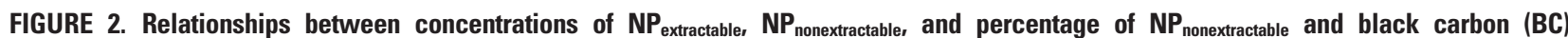
content in sediments. The lines represent linear regression in surface sediments $(\downarrow)$ and sedimentary core $(\square)$. (a) $N P_{\text {extractable, }} p=0.177$,

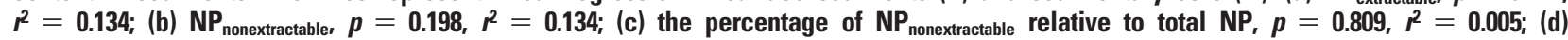
$\mathrm{NP}_{\text {extractable, }} p=0.007, t^{2}=0.211$; (e) $\mathrm{NP}_{\text {nonextractable, }} p=0.334, t^{2}=0.034$; (f) the percentage of $\mathrm{NP}_{\text {nonextractable }}$ relative to total $\mathrm{NP}, p=0.038$, $r^{2}=0.135$

into small precombusted $\left(600^{\circ} \mathrm{C}, 4 \mathrm{~h}\right)$ quartz sample boats. Phosphoric acid (44\%) was added to remove inorganic carbon from the samples. Finally, the samples were analyzed using a total organic carbon (TOC) analyzer (Apollo 9000, TekmarDohrmann, Mason, $\mathrm{OH})$.

BC. BC was referred to as a particulate phase, including soot and charcoal, formed during incomplete combustion of fossil fuels and biomass (25), which has a high degree of aromatic structure and contains reactive oxygenated surface functional groups (26). The analysis procedure was based on Lim's chemical oxidation method (27). $3.0000 \mathrm{~g}$ of dried sediments were weighed into precleaned Teflon test tubes and carefully treated with $15 \mathrm{~mL}$ of $3 \mathrm{~mol} \cdot \mathrm{L}^{-1} \mathrm{HCl}$ over $24 \mathrm{~h}$ to remove carbonate from the sediment matrix. Following repeated centrifuge and rinsing (3-6 times) with filtered ultra pure water, about $15 \mathrm{~mL}$ of $10 \mathrm{~mol} \cdot \mathrm{L}^{-1} \mathrm{HF} / 1 \mathrm{~mol} \cdot \mathrm{L}^{-1} \mathrm{HCl}$ were added to the residue and the reaction allowed to continue at room temperature for a further $24 \mathrm{~h}$. Sediment samples were then subjected to a final $24 \mathrm{~h}$ treatment of 10 $\mathrm{mol} \cdot \mathrm{L}^{-1} \mathrm{HCl}$ after centrifuge and rinsing (3-6 times) until the $\mathrm{pH}$ of rinsing water was $4-5$. The washed acid-treated sediment samples were allowed to dry at $60^{\circ} \mathrm{C}$ until constant weight was obtained. Then the sediment acid-treated was weighed in glass test tubes and treated with $10 \mathrm{~mL}$ of 0.1 $\mathrm{mol} \cdot \mathrm{L}^{-1} \mathrm{~K}_{2} \mathrm{Cr}_{2} \mathrm{O}_{7} / 2 \mathrm{~mol} \cdot \mathrm{L}^{-1} \mathrm{H}_{2} \mathrm{SO}_{4}$. For the oxidation step, samples were kept in test tubes and transferred to a water bath at $55^{\circ} \mathrm{C}$ over $60 \mathrm{~h}$ to remove kerogen from the sediment matrix. Following repeated centrifuge and rinsing (3-6 times) with filtered ultra pure water, the residue was transferred to porcelain crucible and dry at $60{ }^{\circ} \mathrm{C}$ until constant weight $\left(\mathrm{M}_{\mathrm{BC}}\right)$ was obtained. Finally, the carbon content $\left(\mathrm{TOC}_{\mathrm{BC}}\right)$ was measured using Element Analysis instrument (Elenmentar, Germany). Black carbon in sediment can be calculated using the relationship as follows:

$$
\mathrm{BC}(\%)=\left[\left(\mathrm{TOC}_{\mathrm{BC}} \times M_{\mathrm{BC}}\right) /\left(\mathrm{TOC}_{\mathrm{O}} \times 3.0000\right)\right] \times 100
$$

where $\mathrm{TOC}_{\mathrm{O}}$ was the TOC of original sediment.
Statistical Analysis. The statistical program SPSS (Ver 11.0; Chicago, IL) was used to analyze the collected data. Correlations were examined by Pearson's rank correlation test.

\section{Results and Discussion}

Extractable and Nonextractable NP in Surface Sediments. $\mathrm{NP}_{\text {extractable }}$ was detected in all 15 surface sediments (Table 1), and the chromatogram of the extract from site J was shown in SI Figure S2(d). The highest concentration (7 ng/g dw) was found at site I (SI Figure S1), near to the Nanpaiwu River which receives industrial and municipal wastewaters from Tianjin City. The lowest concentration $(0.4 \mathrm{ng} / \mathrm{g} \mathrm{dw})$ was found at site W (SI Figure S1) which is far from Tianjin. These concentration levels were comparable to those $(<1-6.37 \mathrm{ng} / \mathrm{g}$ $\mathrm{dw}$ ) reported for Ulsan Bay, Korea (28), but were much lower than those in Tokyo Bay (120-640 ng/g dw) (15), in marine sediments in Spain ( $<10-1050 \mathrm{ng} / \mathrm{g} \mathrm{dw}$ ) (29), and in the Dutch coastal zone of the North Sea (30) which were close to outfall points of sewage effluent or estuaries.

$\mathrm{NP}_{\text {nonextractable was also detected in all } 15 \text { surface sediments }}$ ranging from $3.0 \mathrm{ng} / \mathrm{g} \mathrm{dw}$ at site $\mathrm{W}$ to $27.3 \mathrm{ng} / \mathrm{g}$ dw at site I, which was several times higher than those of the extractable fractions. SI Figure S2 (d, e) shows the GC-MS chromatogram of the extract from site $\mathrm{J}$, and the peak composition of $\mathrm{NP}_{\text {nonextractable }}$ (SI Figure $\mathrm{S} 2$ (e) was found to be similar to that of $\mathrm{NP}_{\text {extractable }}$ (SI Figure S2 (d)), suggesting that no obvious isomer selective bound reaction to sediment occurred in Bohai Bay. The total concentrations (extractable and nonextractable) of $\mathrm{NP}\left(\mathrm{NP}_{\text {total }}\right)$ were $3.4-34.3 \mathrm{ng} / \mathrm{g}$ dw in the surface sediments. The percentage of $\mathrm{NP}_{\text {nonextractable }}$ relative to $\mathrm{NP}_{\text {total }}$ ranged from $79.6 \%$ at site I to $93.3 \%$ at site $\mathrm{T}$, indicating that $\mathrm{NP}$ is prone to convert to the more stable nonextractable form in sediments.

In addition, the concentration of $\mathrm{NP}_{\text {extractable }}$ at site $\mathrm{J}$ was $2.2 \mathrm{ng} / \mathrm{g} \mathrm{dw}$, similar to that at site $\mathrm{U}$, while the concentration of $\mathrm{NP}_{\text {nonextractable }}$ at site $\mathrm{J}$ was $9.7 \mathrm{ng} / \mathrm{g} \mathrm{dw}$, much lower than that at site $\mathrm{U}(26.8 \mathrm{ng} / \mathrm{g} \mathrm{dw})$ suggesting that the potential to form a nonextractable portion could be associated with the chemical and physical characteristics of sediments. Figure 


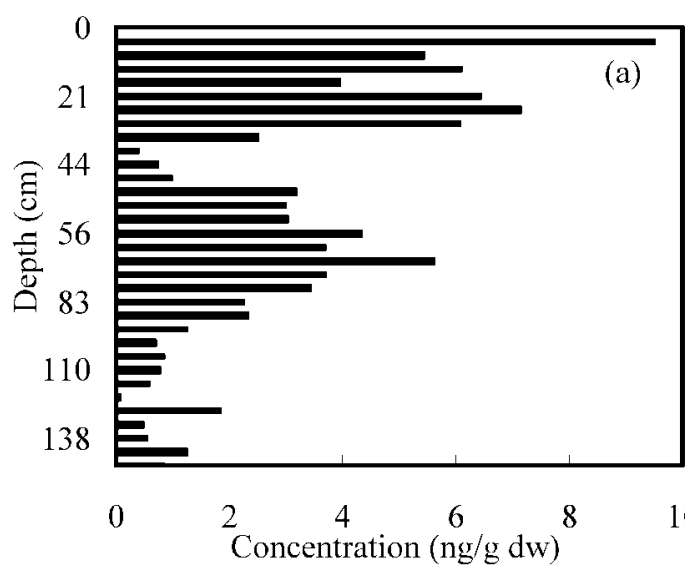

1998

1993

1985

$1981 \stackrel{\varpi}{\approx}$

1972

1962

1954

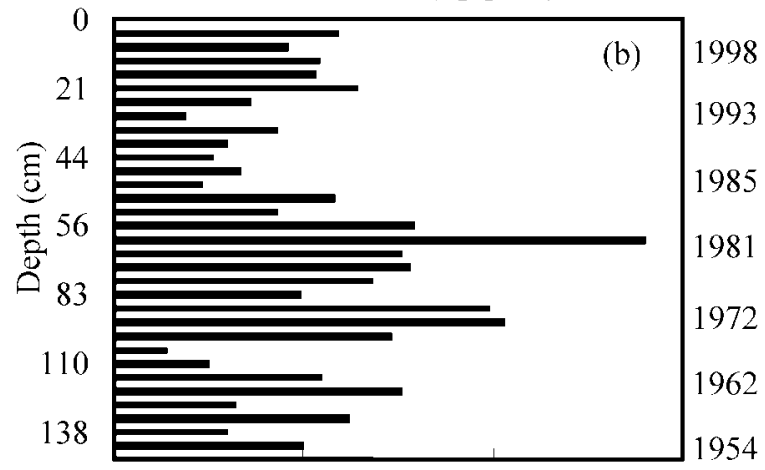

0

$\stackrel{5}{\text { Concentration }(\mathrm{ng} / \mathrm{g} \mathrm{dw})}$

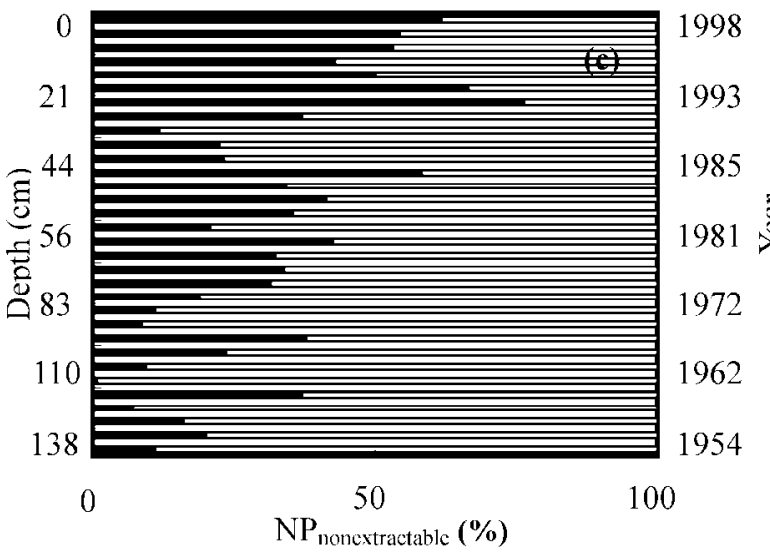

FIGURE 3. Vertical profiles of NP concentrations in the sediment core from Bohai Bay, north China. (a) concentration of

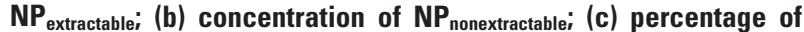
$N P_{\text {nonextractable }}(\%)$

1 shows the relationship between the concentrations of $\mathrm{NP}_{\text {extractable }}, \mathrm{NP}_{\text {nonextractable }}$ and percentage of $\mathrm{NP}_{\text {nonextractable }}$ and TOC in sedimentary samples. It was found that $\mathrm{NP}_{\text {extractable }}$ was significantly correlated to the TOC values in sediments from Bohai Bay $\left(p<0.001, r^{2}=0.662\right)$. A similar phenomenon was also found for some other compounds such as dioxins, hexachlorocyclohexanes (HCHs) and DDTs in Bohai Bay and its adjacent river $(17,31)$, suggesting that the spatial distribution of $\mathrm{NP}_{\text {extractable }}$ in sediments would depend on the TOC contents of sediments. However, no relationship between $\mathrm{NP}_{\text {nonextractable }}$ or percentage of $\mathrm{NP}_{\text {nonextractable }}$ and TOC was obtained (Figure 1(b, c)), which was similar to the results of benzotriazoles in a Pawtuxet river sedimentary core (9). Whereas sedimentary BC was reported to affect the sorption of some hydrophobic organic contaminants (HOCs) to a greater extent than sedimentary organic carbon (OC) (32), there was no correlation between $\mathrm{NP}_{\text {extractable }}$ or $\mathrm{NP}_{\text {nonextractable }}$

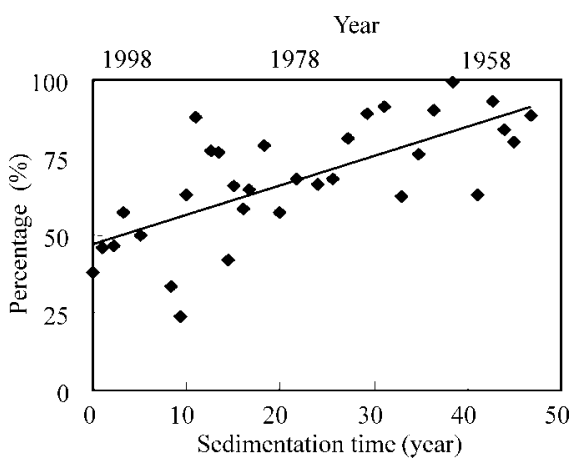

FIGURE 4. Relationship between the percentage of $\mathbf{N P}_{\text {nonextractable }}$ relative total NP and sedimentation time in the sedimentary core from Bohai Bay, north China $\left(p<0.001, r^{2}=0.492\right)$.

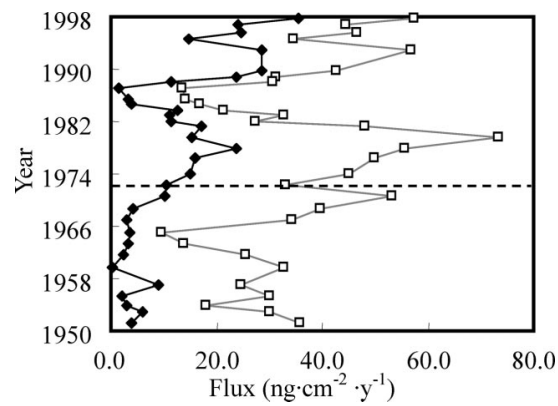

FIGURE 5. Fluxes of NP into Bohai Bay, north China based on total NP concentrations $(\diamond)$ and extractable NP concentration ( $\square$ ).

and $\mathrm{BC}$ content in the surface sediments from Bohai Bay (Figure 2(a-c)).

Sequestration of NP in Sedimentary Core. In the sedimentary core, the concentrations of $\mathrm{NP}_{\text {extractable }}$ ranged from 0.1 to $9.5 \mathrm{ng} / \mathrm{g} \mathrm{dw}$ (SI Table S1). The concentration profile of $\mathrm{NP}_{\text {extractable shows a bimodal distribution (Figure }}$ $3(\mathrm{a}))$. $\mathrm{NP}_{\text {extractable }}$ concentration decreased from the $61-66 \mathrm{~cm}$ layer corresponding to early 1980 s toward the 39-41 cm layer corresponding to late $1980 \mathrm{~s}$, which was probably related to the implementation of environmental regulations starting in 1979. The obvious increasing trend observed from late 1980s might be related to the increase of its production in 1990s (SI Table S2) due to the rapid economic growth of China (33). In the deeper sections of the sediment core (>66 $\mathrm{cm})$, the concentrations of $\mathrm{NP}_{\text {extractable }}$ showed a decreasing trend toward the bottom layer deposited in 1950s.

The concentrations of $\mathrm{NP}_{\text {nonextractable }}$ in the core ranged from 1.4 to $14 \mathrm{ng} / \mathrm{g} \mathrm{dw}$ (SI Table S1). Figure 3(b) shows the vertical profile of $\mathrm{NP}_{\text {nonextractable }}$ in this core. It was found that, the highest concentration of $\mathrm{NP}_{\text {nonextractable was }} 14 \mathrm{ng} / \mathrm{g} \mathrm{dw}$ at a depth of 61-66 cm deposited around 1980 followed by $10.3 \mathrm{ng} / \mathrm{g} \mathrm{dw}$ at a depth of $94-99 \mathrm{~cm}$ corresponding to late 1960s, which was different from that of extractable fraction. The percentage of $\mathrm{NP}_{\text {nonextractable }}$ relative to $\mathrm{NP}_{\text {total }}$ along the core was calculated to be in the range from 23.8 to $99 \%$. It is clear that while the percentages of $\mathrm{NP}_{\text {nonextractable }}$ relative to $\mathrm{NP}_{\text {total }}(23.8-57.3 \%)$ in the surface sediments $(7-36 \mathrm{~cm})$ corresponding with the most recent decade were lower than those in deeper sediments (57.5-99\%), except for the depth $49-51 \mathrm{~cm}(41.8 \%)$ (Figure 3(c)). This increasing trend of the percentage of $\mathrm{NP}_{\text {nonextractable }}$ relative to $\mathrm{NP}_{\text {total }}$ with sedimentation time (or depth in sediment core) was similar with that of C1-benzotriazole in the Pawtuxet River Core (9) as shown in SI Figure S3. The relationships between the percentage of $\mathrm{NP}_{\text {nonextractable }}$ and TOC or BC content were shown in Figure 1(f) and Figure 2(f), respectively. The percentage of $\mathrm{NP}_{\text {nonextractable }}$ decreased with increasing $\mathrm{TOC}$, and vice versa 
for the relationship with $\mathrm{BC}$ content $(p<0.05)$. However, considering no correlation between the percentage of $\mathrm{NP}_{\text {nonextractable }}$ and TOC or BC content in surface sediments (Figure 1(c) and Figure 2(c)), it is difficult to explain the role of TOC or BC on the sequestration of NP in sediments.

Aging and biodegradation can be expected to be two main factors influencing the percentage of $\mathrm{NP}_{\text {nonextractable relative }}$ to $\mathrm{NP}_{\text {total }}$ in the sediment core. Since NP is not biodegradable in anaerobic environments $(34,35)$, the effects of biodegradation on the percentage of $\mathrm{NP}_{\text {nonextractable }}$ relative to $\mathrm{NP}_{\text {total }}$ could be neglected. Therefore, the sequestration rate of NP in the sedimentary core was defined as the following relationship between the percentage of $\mathrm{NP}_{\text {nonextractable }}$ relative to $\mathrm{NP}_{\text {total }}$ and sedimentation time (years aging) using a simple linear regression (eq 2).

$$
\text { percentage }(\%)=a+b \times T
$$

where percentage (\%) is the concentration percentage of $\mathrm{NP}_{\text {nonextractable }}$ relative to $\mathrm{NP}_{\text {total }} ; T$ is the sedimentation time, and $b$ is defined as the sequestration rate of NP in sediment. Figure 4 shows the relationship between the concentration percentage of $\mathrm{NP}_{\text {nonextractable }}$ relative to $\mathrm{NP}_{\text {total }}$ and sedimentation time in the sedimentary core. The percentage of $\mathrm{NP}_{\text {nonextractable }}$ relative to $\mathrm{NP}_{\text {total }}$ appears to increase with increasing sedimentation time in the sedimentary core (eq 3).

percentage $(\%)=47.286+0.9415 \times$

$$
T\left(r^{2}=0.492, n=32, p<0.05\right)
$$

From eq 3 , the sequestration rate of NP in the core was determined to be $0.94 \% \cdot \mathrm{a}^{-1}$, which is the first time that a quantitative estimate of the sequestration rate of NP in sediment was obtained from a field investigation.

Fluxes. In previous studies, fluxes were estimated only using the concentration of extractable fraction of chemicals, neglecting the nonextractable fraction. As shown in Figure 5 , without regard to the presence of $\mathrm{NP}_{\text {nonextractable, the flux }}$ was relatively low $\left(0.2-9.1 \mathrm{ng} /\left(\mathrm{cm}^{2} \cdot \mathrm{a}\right)\right)$ in the sedimentary layer deposited in the 1950s, and subsequently increased to $23.7 \mathrm{ng} /\left(\mathrm{cm}^{2} \cdot \mathrm{a}\right)$ in the $100-105 \mathrm{~cm}$ layer corresponding to the late 1970s. It was found that the maximum value of flux was $57.5 \mathrm{ng} /\left(\mathrm{cm}^{2} \cdot \mathrm{a}\right)$, and occurred in recent years.

On the other hand, when considering $\mathrm{NP}_{\text {nonextractable }}$ in sediments, the fluxes of NP were estimated in the sediments by eq 4 :

$$
\text { flux }=\left(C_{\mathrm{E}}+C_{\mathrm{N}}\right) \times R \times F F
$$

where $C_{\mathrm{E}}$ and $C_{\mathrm{N}}$ are the concentrations of $\mathrm{NP}_{\text {extractable }}$ and

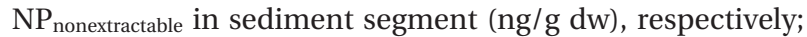
$R$ is the sedimentation rate in sediment segment $(\mathrm{cm} / \mathrm{a})$, and $\mathrm{FF}$ is the density of the location $\left(\mathrm{g} / \mathrm{cm}^{3}\right)$. As a result, estimated fluxes were about 1.3-8.5 times higher than those in the extractable fraction in layers $(<83 \mathrm{~cm})$ deposited after the 1970 s, and its vertical profile was similar to that estimated by the extractable fraction after the 1970s. In addition, the maximum value of flux was $73.2 \mathrm{ng} /\left(\mathrm{cm}^{2} \cdot \mathrm{a}\right)$ occurred around 1980 , and the flux in the layer $(\geq 83 \mathrm{~cm})$ deposited before the 1970s fluctuated, which is obviously different from that of the extractable fraction in the same layers.

Thus, this paper first clarified the sequestration of NP in a sedimentary core from Bohai Bay, which could not be neglected, for the studies of the long-term fate, bioavailability and risk assessment of NP in sediment. The sequestration of NP in sediments based on its total bound fraction should be further investigated, considering that only alkaline hydrolysis procedure was applied to release the bound NP in this study.

\section{Acknowledgments}

Financial support of the National Basic Research Program of China [2007CB407304] and the National Natural Science Foundation of China [40632009, 50525824] are gratefully acknowledged. The manuscript benefited greatly from the comments of two anonymous reviewers.

\section{Supporting Information Available}

Additional information as noted in text. This material is available free of charge via the Internet at http:/ / pubs.acs.org.

\section{Literature Cited}

(1) Alexander, M. How toxic are toxic chemicals in soil. Environ. Sci. Technol. 1995, 29 (11), 2713-2717.

(2) Hatzinger, P. B.; Alexander, M. Effect of aging of chemicals in soil on their biodegradability and extractability. Environ. Sci. Technol. 1995, 29, 537-545.

(3) Tang, J.; Carroquino, M. J.; Robertson, B. K.; Alexander, M. Combined effect of sequestration and bioremediation in reducing the bioavailability of polycyclic aromatic hydrocarbons in soil. Environ. Sci. Technol. 1998, 32, 3586-3589.

(4) Chung, N.; Alexander, M. Effect of concentration on sequestration and bioavailability of two polycyclic aromatic hydrocarbons. Environ. Sci. Technol. 1999, 33, 3605-3608.

(5) Chung, N.; Alexander, M. Differences in sequestration and bioavailability of organic compounds aged in dissimilar soils. Environ. Sci. Technol. 1998, 32, 855-860.

(6) Beller, H. R.; Simoneit, B. R. T. Hexachlorophene distributions in estuarine sediments. Bull. Environ. Contam. Toxicol. 1988, 41, 645-650.

(7) Beller, H. R.; Simoneit, B. R. T. PCBs and hydrocarbons: distributions among bound and unbound lipid fractions of estuarine sediments in Organic Marine Geochemistry. ACS Symposium Series 305; American Chemical Society: Washington, DC, 1986, 198-214.

(8) Schwarzbauer, J.; Ricking, M.; Littke, R. DDT-related compounds bound to the nonextractable particulate matter in sediments of the Teltow Canal, Germany. Environ. Sci. Technol. 2003, 37, 488-495.

(9) Reddy, C. M.; Quinn, J. G.; King, J. W. Free and bound benzotriazoles in marine and freshwater sediments. Environ. Sci. Technol. 2000, 34, 973-979.

(10) During, R. A.; Krahe, S.; Gath, S. Sorption behavior of nonylphenol in terrestrial soils. Environ. Sci. Technol. 2002, 36, 40524057.

(11) Nonylphenol in the environment: a critical review. Available atwww.emba.uvm.edu/ nhayden/npreview.pdf.

(12) Marcomini, A.; Pojana, G.; Sfriso, A.; Quiroga Alonso, J. M. Behavior of anionic and nonionic surfactants and their persistent metabolites in the Venice Lagoon, Italy. Environ. Toxicol. Chem./ SETAC 2000, 19 (8), 2000-2007.

(13) Shang, D. Y.; MacDonald, R. W.; Ikonomou, M. G. Persistence of nonylphenol ethoxylate surfactants and their primary degradation products in sediments from near a municipal outfall in the Strait of GA, British Columbia, Canada. Environ. Sci. Technol. 1999, 33, 1366-1372.

(14) Ferguson, P. L.; Iden, C. R.; Brownawell, B. J. Distribution and fate of neutral alkylphenol ethoxylate metabolites in a sewageimpacted urban estuary. Environ. Sci. Technol. 2001, 35, 24282435.

(15) Isobe, T.; Nishiyama, H.; Nakashima, A.; Takada, H. Distribution and behavior of nonylphenol, octylphenol, and nonylphenol monoethoxylate in Tokyo metropolitan area: their association with aquatic particles and sedimentary distributions. Environ. Sci. Technol. 2001, 35, 1041-1049.

(16) Marcomini, A.; Pojana, G.; Sfriso, A.; Orio, A. A. Persistent metabolites of alkylphenol polyethoxylates in the marine environment. Mar. Chem. 1990, 29, 307-323.

(17) Hu, J. Y.; Wan, Y.; Shao, B.; Jin, X.; An, W.; Jin, F.; Yang, M.; Wang, X.; Sugisaki, M. Occurrence of trace organic contaminants in Bohai Bay and its adjacent Nanpaiwu River, North China. Mar. Chem. 2005, 95, 1-13.

(18) Ferguson, P. L.; Bopp, R. F.; Chillrud, S. N.; Aller, R. C.; Brownawell, B. J. Biogeochemistry of nonylphenol ethoxylates in urban estuarine sediments. Environ. Sci. Technol. 2003, 37, 3499-3506.

(19) Jin, F.; Hu, J.; Yang, M. Vertical distribution of nonylphenol and nonylphenol ethoxylates in sedimentary core from the Beipaiming Channel, North China. J. Environ. Sci. China 2007, 19, 353-357. 
(20) Kannan, N.; Yamashita, N.; Petrick, G.; Duinker, J. C. Polychlorinated biphenyls and nonylphenols in the sea of Japan. Environ Sci. Technol. 1998, 32, 1747-1753.

(21) Hu, J.; Jin, F.; Wan, Y.; Yang, M.; An, L.; An, W.; Tao, S Trophodynamic behavior of 4-nonylphenol and nonylphenol polyethoxylate in a marine aquatic food web from Bohai Bay, north China: comparison to DDTs. Environ. Sci. Technol. 2005 39, 4801-4807.

(22) Yamashita, N.; Kannan, K.; Hashimoto, S.; Miyazaki, A.; Giesy, J. P. Estrogenic potency of individual nonylphenol congeners isolated from technical mixtures. Organohalogen Compd. 1999, $42,121-125$.

(23) Wang, H.; Jiang, Y.; Li, J.; Xia, W.; Strydonck, M. V.; Goodbred, S. L.; Kang, H. H ${ }^{14} \mathrm{C},{ }^{137} \mathrm{Cs}$, and ${ }^{210} \mathrm{~Pb}$ dating and accelerated tendency of the present sedimentation rate along the Laolangtuozi coast of the Bohai Bay. Geol. Bull. China. 2003, 22 (9), 658-664.

(24) Li, J.; Wang, H.; Xia, W. L.; Goodbred, S. L.; Kang, H.; Zhang, Y. F. ${ }^{210} \mathrm{~Pb}_{\text {exc }}$ and ${ }^{137} \mathrm{Cs}$ dating and modern sedimentation rate on the western coast of Bohai Bay. Geol. Surv. Res. 2003, 26 (2), 114128. Chinese.

(25) Gustafsson, O.; Gschwend, P. M. Soot as a strong partition medium for polycyclic aromatic hydrocarbons in aquatic systems. In Eganhouse, R. P. Ed., Molecular Markers in Environmental Geochemistry; American Chemical Society: Washington, DC, 1997, 365-381.

(26) Weber, W. J.; Huang, W. L.; LeBoeuf, E. J. Geosorbent organic matter and its relationship to the binding and sequestration of organic contaminants. Colloids Surf. A 1999, 151, 167-179.

(27) Lim, B.; Cachier, H. Determination of black carbon by chemical oxidation and thermal treatment in recent marine and lake sediments and cretaceous-tertiary clays. Chem. Geol. 1996, 131, $143-154$.
(28) Khim, J. S.; Lee, K. T.; Kannan, K.; Villeneuve, D. L.; Giesy, J. P.; Koh, C. H. Trace organic contaminants in sediment and water from Ulsan Bay and its vicinity, Korea. Arch. Environ. Contam. Toxicol. 2001, 40, 141-150.

(29) Petrovic, M.; Fernandez-Alba, A. R.; Borrull, F.; Marce, R. M.; Mazo, E. G.; Barcelo, D. Occurrence and distribution of nonionic surfactants, their degradation products, and linear alkylbenzene sulfonates in coastal waters and sediments in Spain. Environ. Toxicol. Chem./SETAC 2002, 21, 37-46.

(30) Jonkers, N.; Laane, R. W. P. M.; De Voogt, P. Sources and fate of nonylphenol ethoxylates and their metabolites in the Dutch coastal zone of the North Sea. Mar. Chem. 2005, 96, 115-135.

(31) Wan, Y.; Hu, J.; Liu, J.; An, W.; Tao, S.; Jia, Z. Fate of DDT-related compounds in Bohai bay and its adjacent Haihe basin, north China. Mar. Pollut. Bull. 2005, 50, 439-445.

(32) Burgess, R. M.; Ryba, S. A.; Perron, M. M.; Tien, R.; Thibodeau, L. M.; Cantwell, M. G. Sorption of 2, 4'-dichlorobiphenyl and fluoranthene to a marine sediment amended with different types of black carbon. Environ. Toxicol. Chem./SETAC 2004, 23 (11), 2534-2544.

(33) Huang, Z. Z.; Zhang, X. G.; Feng, Q. Y. Development of nonylphenol in China. Fine Specialty Chem. (Chinese). 2002, 10 (14), 5-6.

(34) Ejlertsson, J.; Nilsson, M. L.; Kylin, H.; Bergman, A.; Karlson, L.; Oquist, M.; Svensson, B. H. Anaerobic degradation of nonylphenol mono- and diethoxylates in digestor sludge, landfilled municipal solid waste, and landfilled sludge. Environ. Sci. Technol. 1999, 33, 301-306.

(35) Ying, G.; William, B.; Kookana, R. Environmental fate of alkylphenols and alkylphenol ethoxylates-a review. Environ. Int. 2002, 28, 215-226.

ES071522I 